\title{
Chapter title \\ Improving the mechanical recycling and reuse of mixed plastics and polymer composites
}

\author{
Author \\ Dr. Karnik Tarverdi \\ Reader/Director of Extrusion Technology \\ Wolfson Centre for Materials Processing \\ Brunel University \\ Kingston Lane \\ Uxbridge Middlesex \\ UB8 3PH \\ United Kingdom \\ Karnik.Tarverdi@brunel.ac.uk
}

\begin{abstract}
In this chapter we will explore the possibilities and viability of commercially recycling and reusing of composites and mixed polymer based waste that is difficult and expensive to separate into individual generic polymers for subsequent recycling. The chapter will also attempt to cover legislations that hinder and drive this technology and give sources of information for further examples of polymer recycling in action.
\end{abstract}

\section{Key words}

Mixed polymer waste, composite, recycling, reuse, processing 


\section{Section Headings}

1.0 Introduction

2.0 Thermoplastic and Thermosetting Polymers

2.1 Degradation of polymers

3.0 Polymer Composites

3.1 Composites and mixed plastic waste

4.0 Materials Recycling

4.1 Mixed plastic and polymer composites recycling

4.2. Collection and sorting

4.3 Limitations to mixed plastic reprocessing

4.4 Incentives for recycling

4.5 Quality Assurance and status of regulations driving recycling

4.6 Where can recycled plastics composites and mixed waste plastics be used?

5.0 Consumer Protection

5.1 Consequences for Recycling

6.0 The Powder Impression Moulding (PIM) Process

6.1 Concept of PIM process and products

7.0 Other technologies available for converting mixed waste plastic (composites) into products

8.0 Case Studies, Recycling Archives

9.0 References

10. Additional sources of information 


\subsection{Introduction}

It can be very pleasing to the eye, to the pocket and for the environment when piled mixed plastic, so-called 'rubbish' ready for land fill, is converted to building blocks, hoardings, park benches and many other useful long lasting products. Recycling and reuse of materials is by no means a new concept, since over the last three decades and earlier waste newspaper, cardboard, white paper and glass was recycled and reused. However, other items like polymer based products gained acceptance and momentum towards the end of the 70's as a result of the significant increase for that time, in raw materials costs because of the unexpected rise in the price of crude oil. Recycling of polymer composite is an even more recent occurrence with significant work generated in the latter half of the 1980's. However, in recent years there has been an increase in the use of composite products, particularly in the automotive and construction industries. These consume nearly half of all composites manufactured, therefore the issue of composite recycling and use is becoming very important. Successful composite recycling and use requires incentives, infrastructure, good recycling techniques and markets for the recyclates.

Plastics recycling is of growing importance and interest to the public in general and to governments, in particular because of EU directives, stipulations and fines.

There is no end or beginning to recycling efforts since they are essential to help save and minimise the use of non renewable resources and reduce land fill practices.

There is no universal solution to the problem of mixed plastics recycling. A hierarchy of complementary conservation and disposal techniques are needed to solve the escalating problem of mixed plastic waste and plastic composites that are difficult to sort and separate. Plastics recycling involves a series of processing operations carried out to eventually produce 
secondary materials for the manufacture of different types of products.

\subsection{Thermoplastic and Thermosetting Polymers}

The vast majority of plastics used commercially are thermoplastic polymers. These cover all the commodity materials that are used like:

polyethylene (PE), polypropylene (PP), polystyrene (PS), polyvinyl chloride (PVC),

polycarbonate (PC) and polyethylene terephthalate (PET). For a plastic material to have useful properties the molecules must be of a minimum chain length specific to individual polymers, which is expressed in terms of molecular weight which generally falls in the range between 100,000 and $1,000,000$ and in the case of PET it is expressed in terms of intrinsic viscosity (iv). The property of the component will naturally depend on the chain length and methods of recycling will affect the chain length adversely (Brandrup,1995; Goodship, 2007).

The interaction of polymers is affected by forces of mutual attraction between individual chains and by molecular length and the strength of the chain attractions depends on the type of structure. The strongest forces are exerted by polar groups, and a good example is demonstrated by PVC. Hence, the polar $\mathrm{C}-\mathrm{Cl}$ group produces a relatively strong electric field that attracts neighbouring molecules that also have polar groups which gives PVC a high softening temperature, also called the glass-transition temperature $(\mathrm{Tg})$. The $\mathrm{Tg}$ is the temperature at which, on cooling from the melt, the material freezes to a glassy, brittle state. Below Tg much of the thermal motion of the molecules is quenched since the attractive forces between neighbours are sufficient to demobilise the chains.

When a polymer is subjected to heat and shear the molecules are capable of sliding past each other overcoming the intermolecular attractions, thus above a certain temperature such forces have enough energy to move freely and overcome intermolecular attractions, essentially these types of materials are thermoplastic. It is however possible to produce materials with branched chain structures, which can be linked together and shaped using heat and or catalysts 
with chemical reactions, leading to a cross-linked three dimensional product. These materials cannot be reheated and shaped once the polymer has cross-linked and cured, and they are termed 'thermosetting plastics' Some important commercial examples include phenolic, epoxy, polyester, polyurethane and formaldehyde resins.

These types of materials have to be recycled in a completely different method compared with thermoplastic polymers. (RECCOMP Project, 2008; Palmer, 2009a \& b) (RECCOMP-Recycling of Composites)

The development of integrated polymer compounding technology has been instrumental in establishing an effective strategy for gaining value from thermoset waste. Polyester and phenolic scrap has been derived from car components and other industrial thermoset waste materials.

The principal aim of this technology has been to assess the reinforcing potential of such materials after comminution and subsequent inclusion into selected polymer matrices. (Bream, $1997 \mathrm{a} \& \mathrm{~b})$

The successful reuse of thermosetting materials depends on the capability of reducing the size of the thermosetting waste to a level at which it is suitable as a functional filler. The glass fibre content, fibre length distribution, particle morphology, and the addition of virgin fibres are important factors in determining the reinforcing properties of the filler in composites of the recyclate with base polymers.

Application of this methodology to the preparation of polypropylene composites reinforced with waste thermosetting composites has demonstrated that marked increases in mechanical properties can be obtained when fibre to polymer interfacial bonding is achieved. (Bream, 2001) (Bevis, 1996)

The EU End of life Directive requires that $95 \%$ of a vehicle by weight is to be capable of recovery or reuse by 2015 . This target cannot be reached by metal recycling alone, which only accounts for $76 \%$ by weight of the average passenger car. Plastic parts represent the next largest fraction at 9- 
$12 \%$.

Therefore plastics recycling must be considered if the End of Life Vehicle (ELV) targets are to be met. (ELV Directive, 2000 \& 2006) (ELV regulations 2003) Sheet and Bulk Moulding compounds (SMC/BMC) form the major part of the plastic fraction used on vehicles. The use of these materials is increasing which now includes exterior body panels providing the class A finish and simple manufacture not achievable by competing thermoplastic polymers. (Palmer, 2009b)

Directive 2000/53/EC on End of Life Vehicles (ELV Directive, 2000 \& 2006)

It has been effective since 2005. The Directive aims at reuse, recycling, recovery of ELV and components. Recycling of all plastics from End of Life Vehicles should be continuously improved, and development of markets for recycled materials is being encouraged by the UK Government and the European Commission.

\section{Table 1.0 Recycling and recovery timings}

(ELV Directive, $2000 \&$ 2006)

\subsection{Degradation of polymers}

During primary processing and after use when polymers are being recycled, secondary degradation takes place and the molecular length of the polymer chain is reduced by mechanical and thermal decomposition. The degraded polymer molecular chains are less capable of linking with one another. Also, the melting point of the composite becomes lower and the general physical properties are reduced. (Brandrup, 1995) As molecular length is reduced by degradation (thermal or physical) which can be caused not only by recycling but above all, by ageing, this suggests that the sections of molecule projecting from a chain tangle are the first to be attacked and broken off particularly with semi crystalline polymers. Thus, degraded molecules are less capable, or are even incapable, of linking by bonding together 
with the lowering of the molecular weight

melting point and reduction of toughness in the solid state and the material behaves in a brittle fashion on impact. The Melt Flow Index (MFI) which is the measured gravimetric flow rate of the thermoplastic melt extruded from a die of specific length and diameter, under given conditions of pressure and temperature, is generally higher than the starting materials and also the impact strength isdiminished. This is not universal, however, since the MFI of HDPE initially decreases as the material is recycled.

There is a growing demand to develop and use new products containing high percentages from sustainable, renewable and natural resources that provide properties and performances equivalent to or better than synthetic polymers. Some of the leading polymers competing for demand are: Poly Lactic acid (PLA), modified starches, polyhydroxy buterate (PHB) and polyhydroxyalkanoate (PHA) (Bagrodia, 2008) (Xia, 2007) However, these materials primarily degrade by microbial attack rather than thermal or physic breakdown.

\subsection{Polymer Composites}

Polymer composites consist of either a thermoset or thermoplastic polymer, along with inorganic fillers like calcium carbonate and glass fibres which together build up the structure of the composite.

The physical properties are strongly dependent on the chemical structure and ratio of individual groups in the plastic as well as on the fillers employed. These have a very large influence on the overall spectrum of properties of the polymer composite which includes the additives for the final composite formulation.

Polymer composites are extensively used in the manufacture of lightweight, flame retardant and abrasion resistant components for the automotive, aeronautical industries and household goods. Composite materials made of various plastics and additives include: textile-reinforced plastic hoses, glass and natural fibre reinforced sheeting, metal reinforced profiles for windows, carpet, cable 
wastes, tyres, composite bumpers and many more.

These composites generally end up in landfill, but there are modern sorting and recycling methods developed to divert thousands of tonnes of composites from landfill to recycling for the manufacture of new and novel composite materials. (RECCOMP \& PIM Projects, 2008 \& 2009) respectively.

All composite waste materials need to be size reduced prior to recycling by using slitting rollers, hydraulic shears and shredders followed by post size reduction using robust granulators some with rotors designed to cut through metal containing parts which can be reduced in size between 2 and 6 $\mathrm{mm}$ which is ideal for the subsequent separation process to take place. These include magnetic, gravity cascade, air and cross flow separators to separate metal, fibre and some fractions of polymers.

Ideally it would be best just to size reduce and reconstitute the mixed plastic composite waste into a new composite and the PIM process which is described in section 6.0. was designed to bring together the fine ground composite by applying thermal energy and compression force sandwiching the waste composite between single polymer sheeting. (PIM Project, 2009)

\subsection{Composites and mixed plastic waste recycling}

To manufacture composites for a particular component use, the individual ingredients that make up the composite are tailor made to suit the purpose for which the component is intended. However, for efficient recycling of composites and mixed plastic wastes, the mechanical properties obtained are usually inferior owing to the separation of phases and incompatibility issues, as molecules repel each other and phase separation occurs. If, therefore, the second polymer is not very finely and uniformly dispersed in the first, it causes precipitates that have no connection with the surrounding phase, as can be seen by light microscopy. Different polymers are usually mutually incompatible, i.e. if one phase is well dispersed in the 
second phase, the particles can be bound with the first by compatibilisers (molecules that join the phases) to attain exceptional properties, in particular high impact strength and good optical surfaces. Attempts to apply this method to plastic wastes are also being made, and the prospects of obtaining useful products are likely to be good if uniform dispersion on a large scale can be guaranteed; Mixtures of mutually incompatible polymers, can be made more impact resistant by this means. However, accurately defined and uniform polymer composites are required, with a well dispersed second phase.(Bream, 2001)

\subsection{Materials Recycling}

In general, mechanical and physical properties of most polymeric materials are quite similar, but these properties are enhanced when blending with other organic and inorganic polymers, fillers and fibres to make composites.

Discussions about composites recycling and reuse are difficult without basic knowledge and understanding about composite behaviour during its first life cycle and the changes envisaged during recycling and eventual reuse.

But as it is difficult with just a single source of polymeric waste because different polymers need different processing conditions, to try and reconstitute polymer composite waste is naturally even more complex to deal with. (Goodship, 2007)

\subsection{Mixed plastic and polymer composites recycling}

Plastic waste is generated during production and processing of components but at this stage plastics can be mixed in controlled amounts with the virgin polymers already and put back into the processing line. Once the products get into the market place, for example as packaging or as functional components, are disposed of, and their end of use has been dealt with by collection and disposal in land fill as mixed plastic waste. 
If however, this type of plastic waste is easy to identify and sort, then recycling can be cost effective.

Generally, though, the separation techniques used cannot distinguish and separate all the plastics and it could then become very expensive and labour intensive to physically hand separate them. As a result of this, the bulk of the mixed waste plastics are either collected and land filled, stored for future separation or sent overseas to be hand sorted and sold for low value recycling or disposal. In some instances, it is viable to identify and separate the easily separable polymers like HDPE for high value use, while the rest of the fractions are sold as cheap scrap or sent for land fill because the value of the this is below the general $£ 80 /$ tonne threshold.

The UK uses about 7 million tonnes of plastic per annum in a very wide range of applications. Of the annual total, approximately 1 million tonnes are recycled, this includes 500,000 tonnes of plastic packaging recovered under the Packaging Waste Regulations. (Packaging Waste Regulations, 2007). Figure 1, gives an indication of plastics in household waste in the UK. Recycling of polymers from a single source has been quite well established and in more recent developments there are the closed loop recycling techniques established, like the HDPE Milk Bottle and the PET bottle schemes where companies like Coca Cola are signing up to using the recycled bottles with their virgin PET, and Vannplastic in the UK with their Ecodek label are successfully extruding large tonnages of recycled polyolefins with high loadings of wood fibre for decking and many other applications. But when it comes to recycling of mixed waste with composites, to establish a closed loop system will not only be more difficult, it will also be impractical since the virgin composite users would find it difficult to use recycled composites with diminished properties as a consequence. However the composite waste could have a high value as a recyclate provided the collection, sorting and recycling is well concieved. (www.closedlooprecycling, vannplastic)

\subsection{Collection and sorting}

Collection and sorting economics, particularly within the domestic waste stream, for 
plastic packaging from municipal waste streams of identifiable items is becoming streamlined and sophisticated. For example, from the 2008 WRAP report and survey analysis, the total quantity of plastic bottles collected in the UK in 2007 was 181,887 tonnes. This is a considerable increase of approximately $68 \%$ on the 2006 total quantity of 108,453 tonnes. The number of local authorities offering plastic bottle collections this year was recorded as 437 or $92 \%$, where estimates based on respondents returns to last year's survey are included.

Approximately 525,300 tonnes of plastic bottles were consumed in households throughout the UK in 2007. If the total quantity of plastic bottles actually collected in 2007 was 181,887 tonnes, then approximately $35 \%$ of plastic bottles that were consumed by households were collected. Using this consumption figure, the trend indicates collection rates of $50 \%$, $71 \%$ and $94 \%$ in 2008, 2009 and 2010, respectively, but the likely outcome is that the trend will plateau at around the projected 2009 rate of $71 \%$ as the growth in the number of collections slows. (WRAP, 2008)

Collections of mixed plastic waste using municipal waste streams are well organised but the separation and identification of the plastics into different generic polymers is difficult, expensive and time consuming. There are mixed plastic conversion methods that are being used to minimise sorting and extensive cleaning, but as yet most of the methods being used are at their prototype and experimental stages.

Even when collections of mixed bottles alone are targeted in their plastic bottle collection schemes, the bottles are most commonly made from HDPE and PET and are the type of bottles currently of highest value to local authorities. However, due to the system of household collections it is not possible to receive only the desired materials, due to human error and the difficulty of identifying them. From an analysis of plastic bottles received by Valpak Northwest's Materials Recycling Facility (MRF) in July to December 2007, a typical profile of plastic bottles collections in the UK was established. Whilst the majority of materials 
received (77\%) were HDPE and PET bottles, there was approximately $23 \%$ that could be classified as contaminated with included materials such as aluminium and steel cans, and other unsuitable plastics from labels and caps.

With increasing recycling and landfill targets, more local authorities are investigating the potential of introducing new technologies to improve efficacy in waste management. This in turn has the potential to affect the way in which plastic bottles and other household plastics are handled. As part of the survey, local authorities were asked what plans they have, if any, for introducing new technologies for waste management and recycling. In order to optimise recycling and comply with new impending legislation, many local authorities have implemented other plastic collection schemes from homes and schools, including Waste Electrical and Electronic Equipment (WEEE) and agricultural plastics from farms (such as silage film). (WRAP, 2008)

\subsection{Limitations to mixed plastic reprocessing}

Unfortunately there is limited investment in technology to improve and increase efficacy and capacity of re-processors, which has hindered mixed plastic reprocessing. Furthermore there has been a lack of sustained competitive pricing for recyclates compared to virgin polymers. Also, prices are volatile and there is a lack of mechanisms to deal with these fluctuations.

\subsection{Incentives for recycling}

Without government aid and incentives, it is difficult for recyclers to embark on developing machinery and technology for viable recycling methods. The UK Government through TSB and WRAP is investing in many projects that are directly involved in mixed waste recycling procedures. (PIM \& RECCOMP Projects, 2009 \& 2008) respectively.

\subsection{Quality Assurance and status of regulations driving recycling}


The extent to which products are recycled and who takes responsibility for managing and collection of used products, is influenced by regulatory requirements. The regulations that drive the process are either associated with virgin manufacture or the cost of waste. There are several European Directives and regulations that impact composite waste management, collection and recycling, for example:

- Waste Framework Directives 2008/98/EC, 75/442/EEC, 91/156/EEC, 91/692EEC, 85/59/EC, 96/350/EC.

- Hazardous Waste Directives 91/689/EEC, 94/31/EC.

- Waste Decision 94/3/EC, European Waste Catalogue.

- Council Directive 1999/31/EEC on Landfill of Waste and Council Decision 2003/33.

- Directive 2000/76/EEC on the incineration of waste Integrated Pollution Prevention and Control.

- IPPC Directive 96/61ECPackaging and Packaging Waste Directive 94/62/EC.

- Directive 2000/53/EC on End of Life Vehicles.

- Directive 2002/96/EC on Waste of Electrical and Electronic Equipment, Directive 2002/95/EC on Hazardous Substances in WEEE.

The recovery and recycling of plastics waste, with reference to ISO 15270:2008 has been formulated to help plastics recyclers and collectors to meet a standard and the process can be summarised as follows: regulations, rules and standards that govern new plastics apply to all activities related to the recycling of used plastics, and their full life cycle.

With recent legislations in place it is now easier to comply with the conditions applied to the recycling and reuse of plastics composites.

(www.iso.org, ec.europa.eu/environment/waste/legislation/a.htm)

In this context it should be mentioned that recyclers have to satisfy quality assurance legislations concerning the recycling of materials in the UK and EU that has been enacted to reduce burdens on landfill sites and to meet the targets for recycling set by the 
European Commission. (www.defra.gov.uk/environment/waste/europe/index)

\subsection{Where can recycled plastics composites and mixed waste plastics be used?}

Plastic recyclates are not excluded in principle from being used in almost any application and including food packaging.

There needs to be stringent legislation to control the quality of the recyclates and of the reprocessing plant. In addition, the recyclates have to satisfy existing regulations like the EU regulations $89 / 109,90 / 128$ and $92 / 39$ and many more since.

An international standard designed to assist in the development of a world wide market for plastics recovery and recycling was launched in July 2008. The standard ISO 15270:2008, "Plastics Guidelines for the recovery and recycling of plastics waste", was compiled after input from relevant international industry bodies and stakeholder associations. It is hoped that the standard will help establish a sustainable infrastructure for recovery/recycling and a sustainable market for the manufactured products of the converted materials.

As an example, The British Standards Institute (BSI) and Waste Resource Action Programme (WRAP) has created new standards for recycling the 46 million used tyres generated each year in the UK.

Two Publicly Available Specification (PAS) documents have been developed to provide a clear guidance to the "measures and procedures needed to produce recycled material such as shred, crumb, powder and tyre bales to specific consistent grade and quality."

According to WRAP, the PAS documents, which set out voluntary specifications promise to be a useful resource in what is "an industry historically lacking guidance." PAS 107 refers to the manufacture and storage of size-reduced tyres derived from rubber materials, while PAS 108 covers the production of tyre bales for use in construction.

(www.bsiglobal.com, wrap.org.uk) 


\subsection{Consumer Protection}

Consumer protection in most areas of use of recyclate products is well established and the same protection needs to be applied to the recycled composite applications e.g. in areas of food packaging, milk and beverage containers, toys, cosmetics and pharmaceuticals, It is expected that, initially in these areas, composite recyclates will not be the targets for the consumption of large percentages of composite recyclates. The prime initial target areas will be with packaging, equipment, support structures and pipes etc.

\subsection{Consequences for Recycling}

Because of the escalating price of oil the temptation to use recycled composites to conserve the use of virgin materials is becoming more desirable. At present (November 08 - May 09) due to the exceptional circumstances that have lead to the economic downturn, the price of oil and thus the prices of commodity plastics have fallen. Thus, there is a risk that companies might try and cut corners and use the recyclate without the necessary property evaluation and certification to keep costs down. There was a time when persuading companies to recycle their off cuts was problematic and only legislation could persuade its use, but times are changing.

Regulations relating to the recovery and use of polymeric composites must be followed at all times, and recycling plants have to be properly set up with approval of quality checks by local authorities.

There needs to be producer liability, similar to that for the use and retailing of virgin or single source recycled materials. In some instances the polymeric composites should not be recycled but perhaps incinerated for energy recovery, as long as the plants meet with stringent regulations to prevent escape of toxic fumes and improper disposal of toxic ash. The UK Government has revised the recycling and recovery targets as part of the compliance with the packaging and packaging waste directive 2004/12/EC requiring that $25.5 \%$ of plastic to be recycled in 2010. Plastics recycling from domestic and some industrial waste is currently 
uneconomical due to the costs of the separation of the plastics and the low value of the markets for plastics recyclate. For mixed plastic waste to become a viable and market driven process, new enduse applications need to be developed, or processes that allow the manufacture of higher value products to use recyclate. For example, using the PIM process to manufacture boards.

(PIM Project, 2009)

In addition, Local Authorities must recycle 30\% of domestic and household waste by 2010 according to the EU implementation of the landfill directive 1999/31/EC. In 2002 little over 15,000 tonnes of plastic packaging waste of the domestic waste stream was recycled, from a potentially recoverable total of 1.5 million tonnes. The majority of plastics waste from the UK building and construction industry is land filled and only very little is recycled. There are indications that there is over 570,000 tonnes per annum of potentially recoverable plastic composite waste arising in the construction waste stream (Waste Watch - Plastics in the UK Economy 2003).

(www.wastwewatch.org.uk)

\subsection{The Powder Impression Moulding (PIM) process}

The Powder Impression Moulding (PIM) (PIM Project, 2009) process is at present being further developed by the Wolfson Centre for Materials Processing Brunel University and PERA with consortium partners involving producers, end users and collectors of mixed plastic waste like Tesco and Bovis Lend Lease, Severnside Recycling and Environmental Recycling Technologies Plc.(ERT). The PIM process should allow manufacture of Returnable Transit Packaging (RTP) for the Food and Drinks industry and products for the construction industry, having up to $80 \%$ mixed plastic recycled content as the core material with no loss of aesthetics or functionality.

The PIM process technology concept when fully developed has the potential to add significant value to the plastics recycling industry through the incorporation of up to $80 \%$ mixed plastic polymer waste into value-added products. However, in order to realise the concept, there is a need to create a robust supply chain for processing the feedstock into PIM tolerant microparticles and to 
demonstrate the applications of PIM to gain industry confidence in the products that can be produced. In order to facilitate this venture the organised consortium of industry, university and research partners is undertaking a research project funded by TSB. The partners hope to develop the technology further and to evaluate new robust products of mixed plastic waste composites, particularly in renewable transport packaging for the food and drink industry and products for the construction industry. Most companies are taking materials recycling, sustainability and decreasing carbon footprint issues very seriously. E.g. Marks and Spencer is spending $£ 200 \mathrm{M}$ over five years starting from January 2007, on a wide ranging “eco-plan” and, in general, sustainability campaigners have welcomed the initiative as a progressive project of its kind by a mainstream retailer in the UK. Furthermore, a Bovis Lend Lease UK policy document on sustainability sets out the following goals by the end of 2010: reduce carbon emissions by $20 \%$ compared with 2008 levels, reduce waste to landfill by $70 \%$ compared to 2007 levels, deliver projects which are rated BREEAM "Excellent" and encourage clients to aim for BREEAM "Very Good" as a minimum, develop a procurement policy to ensure procurement of significant materials from sustainable sources. (www.breeam.org)

(BREEAM is an environmental assessment method that can be used to assess the environmental performance of any type of building (new and existing))

The majority of polymer reprocessing is performed using polymer obtained from clean industrial sources such as LDPE from wrappings and sheeting, PP from transit packaging and HDPE and PET from crates and bottles. These sources require minimal reprocessing, contain low levels of contamination and yield high quality single polymer recyclate that is sold into the market as single source virgin polymer (wrap.org.uk). The recyclates of composites and mixed, contaminated or domestic polymer waste is uneconomical and unattractive to recyclers (see figure 2), because it requires extensive sorting and cleaning as part of the reprocessing cycle and most of this type of mixed waste polymers is land filled. Very small quantities of this type of polymeric waste is used to 
manufacture products such as plastic lumber, and these products are of low value applications During melt processing of the mixed plastic some polymers will melt, others will remain solid and polymers having different polar groups will tend to phase separate. Furthermore, and the presence of large solid particles within the matrix increases the chances of stress cracking and poor performance.

\subsection{Concept of the PIM process and products}

The concept of the PIM process (see figure 3), which uses micronized mixed plastic waste, involves applying a film of virgin polymer to the interior of a hot mould tool. The core material comprising of powdered mixed recyclate and blowing agent is then sprayed onto the lower half of the mould tool. A lid, also coated with virgin or single source polymer, is then lowered onto the lower half of the mould and the halves of the mould are clamped together. The mould is then placed into a heat curing oven where the core material fuses together under pressure generated partly by the blowing agent, after which the mould is cooled and the product removed. This process does not require the complete melting of all the constitutive particles since the top and bottom virgin or single source polymer sheeting holds the core composite together and allows the main loading structure of the manufactured component. Depending on the final application, a wide range of mixed polymer waste including a percentage of inorganic fillers and fibres can be contained within the core of the composite.

The mixed polymer composite waste can be utilised within the construction industry and Returnable Transit packaging (see figure 4). (PIM Project, 2009)

The 2004 market for plastic boxes, crates, cases and similar articles for conveyance or packaging of goods was $£ 444$ million (office of National Statistics). Returnable Transit packaging (RTP), which includes stacking containers, folding boxes and large containers, bottle crates and pallets. Major consumers within the industry are the supermarkets who had 15.4 million crates in use in 2000 and UK bakeries. The use of RTP by supermarkets is growing through the organic initiatives of their 
respective businesses and RTP use is also increasing through the organic food growers such as home shopping delivery.

In Europe there are 70 suppliers of RTP to these customers, although the European and UK markets are dominated by less than 10 organisations (http//www.competition-commission.org.uk). The 2002 market for RTP was 517 million, falling to $£ 509$ million in 2003 and $£ 444$ million in 2004. This decline is not linked to a decrease in the demand for RTP, which continues to grow as new applications, such as home delivery, are introduced and with environmental legislation driving greater reuse, but it can be attributed to rising material costs. In 2002 oil prices were about $\$ 23 /$ barrel, in 2004 about $\$ 40 /$ barrel, and in 2008 about $\$ 110-150 /$ barrel, but today (May 2009) it is about $\$ 40 /$ barrel. This represents a tangible opportunity for the development of a technology that allows the incorporation of using mixed plastic composite waste in the manufacture of these products. The 2005 market for building products for the construction industry was $£ 30$ billion (DTI Construction Industry Report), of which $\sim £ 30$ million is represented by plastics products. Over the last 25 years there has been a trend towards the increased use of plastics in the building industry, and it is predicted that in Western Europe the plastics use will increase to about 8 million tonnes by 2010 (Waste Watch - Plastics in the UK Economy. This growth must be balanced against the challenges of implementing sustainable practice within the construction industry, since the energy consumed in building services accounts for 50\% of CO2 emission (DTI).

\subsection{Future technologies for converting mixed waste plastic (composites) into products}

In a recent 2007 RECOUP report (www.recoup.org) it was shown that there is a $£ 430$ cost to the reprocessor for processing polypropylene trays into recyclate, of which $£ 220$ was associated with sorting and cleaning, therefore it is essential to try and minimise sorting and cleaning prior to recycling. The manufacture of products from mixed plastic waste feedstock with appropriate converting technology like the PIM technology will lead to reductions in the use of virgin polymers ( 450 tonnes/month) for manufacturing similar products, resulting in lower energy costs and the 
utilisation of non-renewable resources. The highest proportion of the energy required for the manufacture of products with virgin polymer is needed for the production of the resin feedstock. For example, $90.67 \%(81.5 \mathrm{KJ} / \mathrm{kg})$ of the energy required to produce HDPE pipes relates to the production of the virgin polymer, whilst processing requirements represent only $7.93 \%(7.1 \mathrm{MJ} / \mathrm{kg})$ of the total.

There are many universities and companies researching and working in the development of mixed waste recycling techniques (e.g. Wolfson Centre for Materials Processing, Brunel University the School of Engineering, Computer Science and Mathematics at Exeter University and research establishments like PERA and Smithers RAPRA,) for advancing and extending the possibilities of using mixed plastic waste recycling techniques. As a result, potentially thousands of tonnes of precious materials will be prevented from land fill or being sent overseas with substantial premium payments.

The UK Government and EU Commission have major roles to play in making finances available for advancing and establishing mixed plastic waste technology. In the UK, WRAP and TSB are actively helping research establishments, universities and UK companies to achieve mixed waste recycling techniques. Moreover, an in-depth understanding and evaluation of required composites is being sought, through, for example the Technology Strategy Board's initiatives like, High Value Manufacturing, the use of Sustainable Resources and Energy Saving concepts like Energy Generation and Supply and the Ultra Efficient systems for the market advancement of electric and hybrid vehicles.

\subsection{Case Studies Recycling Archives}

\section{The Construction Centre}


The construction centre has an extensive database for architects and contractors to find recycled and sustainable products in order to help them conform to the Site Waste Management Plans (SWMPs) that came into effect from April 2008.

"The Construction Centre is one of the largest online resources for the building industry and has over 10,000 product manufacturers referenced on the website that can be found by searching over 97,000 product terms. The website also has additional information regarding building regulations, Local Authority planning offices, trade associations and industry publications and also includes UK directories of industry professionals, tradesmen contractors and merchants".

(www.theconstructioncentre.co.uk, therenewableenergycentre.co.uk)

\section{Epwin Group}

Building materials specialist the Epwin Group claims to have developed the first fully recycled PVC-U windows. The unit has been made out of waste from social housing refurbishment project following the replacements of single-glazed first generation windows.

PRW mentions that "Edwin Group's technical director David Wringley said that PVC-U is "hugely recyclable" but the challenge was removing the old building debris prior to reprocessing. The recycling process uses a technical system that removes all traces of rubber, metal and glass and creates a near virgin quality material".

At the 2008 Eco-Build exhibition in London the recycled PVC-U window was exhibited.

\section{Waste PVC-U recycling}

PVC-U sourced mostly from window and door fabricators is being recycled into what a leading wiring accessories manufacturer claims are the 'greenest' cable management products in the industry.

MK Electric (www.mkelectric.co.uk)

MK Electric uses $100 \%$ recycled extruded lengths of PVC in its production process from its established supplier PVC group, a Recovinyl recycler. This means its systems offer the most 
recycled content of the comparable ones on the market. Overall, over $90 \%$ of the company's cable management range, including skirting and trunking, is made from recycled plastics.

Waste PVC-U, including off-cuts and bar lengths, is collected by PVC recyclers from fabricators across the UK and Ireland. It is then processed to remove all contaminants and ground into a high quality blended powder for re-use.

PVC Group director Joanne Makin is said to comment that "as a market leader, MK Electric requires very high grade material to manufacture its products. We have been a long-term supplier to MK Electric for more than 20 years and are committed to supplying a high quality of recyclate using up to date state of the art technology, that enables us to meet the company's quality requirements".

Using PVC recyclate supports MK's commitment to sustainability in two ways; first by diverting over 12,000 tonnes of PVC per year from land fill and secondly, by preserving natural resources with associated savings in energy and providing a significant reduction in carbon emissions. Given the UK construction industry's commitment to improve sustainability across the whole sector, sourcing $100 \%$ recycled products that can truly demonstrate that 'close-loop recycling' can make a significant contribution to providing environmentally-friendly solutions. Managing Director Mike Southgate says manufacturers have a responsibility to make more efficient use of materials. That is a marked change in emphasis on sustainability issues.

Initiatives such as the Code for Sustainable Homes, the 2012 Olympic Construction Commitments and the Government's Waste Resource Action Programme (WRAP) have put sustainability to the top of the agenda for the construction industry.

Recovinyl is funded by the PVC industry body Vinyl 2010 formed to demonstrate commitment to sustainable development. It is backed by the British Plastics Federation and supported by the Waste Resources Action Programme. (www.recovinyl.com, www.recovinyl-wrap flyer 2008).

Boeing and Alenia composites recycling venture (www.alenia-aeronautica.It) 
Composites need to be taken seriously since they play an "increasingly significant role" in the manufacture of more environmental friendly aircraft parts. In July 2008 - Boeing established a joint venture aircraft composite recycling operation with Alenia Aeronautica in Italy, to deal with the significant amounts of high performance composites are used in modern aircrafts.

Milled Carbon of the UK has a pilot scale technology for recovering carbon fibres and is also involved with the project. Boeing is making use of composites in the primary structure of the 787 Dreamliner, and Alenia Aeronauticca is a composite partner in that project supplying fuselage and stabiliser structures, thus ideally placed to reuse recycled compostes in aircrafts PRW mentions that "The initial focus of the venture is to process carbon fibre composite scrap material from Alenia and its supply chain operations. In the longer term, the organisations plan to work with Italian industry and academia to develop new markets for recovered carbon fibre in areas such as automotive and sporting goods. The recovered carbon fibres are said to be suitable for reincorporation into non-critical aircraft composites such as interior linings and seat parts".

SIMS Group (www.eu.simsrs.com),

SIMS Recycling Solutions, a division of the global recycling SIMS Group, has launched its long awaited plastics separation technology (WEEE), Waste Electrical and Electronic Equipment. The company will run the technology across its European WEEE sites.

The majority of the collected recyclate will be post-consumer waste, composed of high-impact polystyrene, acrylonitrile butadiene styrene (ABS) polypropylene and polyethylenes. “Other plastics like polyamides (nylons) will also be present and thus collected, but since they are in smaller quantities, they are left with the waste stream because at present it is not economically viable to recover them". (www.prw.co.uk)

SIMS is expecting to produce 40,000 tonnes of plastics from its European WEEE business by 2010.

\section{Wolfson Centre for Materials Processing, Brunel University}

(Brunel.ac.uk/research/centres), (Tarverdi, 2006) 
Brunel University has collaborated with wall paper manufacturers like Fine Decor, Graham and Brown, Speciality Coatings, Imperial Home Décor Group and material supplier Ineos on the development of extrusion technology that can convert post industrial vinyl wallpaper waste into an added value compound with the inclusion of waste plastisol. These compounds can be either injection moulded or extruded using conventional polymer processing equipment. In the UK approximately 15000-20000 tonnes per annum of post industrial wall paper and plastisol waste is currently land filled.

\subsection{References:}

1. Bagrodia S., (2008) Advanced Materials from Novel Bio-based Resins, ANTEC Cereplast Inc.

2. Bevis M J, Hornsby P R, Tarverdi K and Lee W H., (1994) Recycling of composites, Concise Encyclopaedia of composite Materials, Ed. A. Kelly. Persimmon

3. Bevis M J, Bream C E, Hornsby P R, Tarverdi K and Williams K S., (1996) Proc. $20^{\text {th }}$ Int. BPF Composites Congress, Hinckley, UK

4. Bream C E, Hornsby P R, Tarverdi K and Williams K S., (21-23 April 1997a) “Adding Value to Thermoset Composite Recyclate", Euromat'97, Maastricht

5. Bream C E, Hinrichsen C, Hornsby P R, Tarverdi K \& Williams K S., (1997b) Plastics, Rubber and Composites Processing and Applications 26, 7 303-310 Integrated compounding technology for preparation of polymer composites reinforced with waste materials

6. Bream C E, Hornsby P R., (2001) Comminuted thermoset recyclate as a reinforcing filler for thermoplastics. Part II: structure-property effects in polypropylene compositions. J Mat Sci;36(12):2977-90

7. Brydson J A., Plastics Materials(1996) Iliffe

8. Chawla K K., (1998) Composite Materials $2^{\text {nd }}$ Edition, Springer (ISBN: 0387 98409718.

9. Conversion of Polymer Wastes and Energetics Editors Krause H H, Penninger J M L., Chem Tec Publishing 1994 ISBN: 1895198062

10. European Union End of Life Vehicles (ELV) Directives 2000/53/EC \& 20006/12/EC

11. European Union Landfill Directive 1999/31/EC

12. Gallet C, Kermarrec M., "Molten salts: a promising lead to composite recycling". JEC 
13. Goodship V., (2007) Introduction to Plastics Recycling, $2^{\text {nd }}$ Edition, Smithers RAPRA (ISBN:978 184735078 7)

14. Hornsby P R, and Tarverdi K., (1996); Integrated polymer recycling technology, UK Patent Application

15. Liu Y, Meng L, Huang Y, Du., (2004) Recycling of carbon/epoxy composites. J Appl Polym Sci;94(5):1912-6.

16. McDonough, W and Braungart M., (2002) Cradle to Cradle : remaking the way we make things, North Point Press NY ISBN 0865475873

17. Packing and Packaging Waste Directive 94/62/EC - BEER (In the UK this is implemented through the Producer Responsibility obligations (Packaging waste) Regulations 2007.

18. Palmer J, Ghita O R, Savage L, Evans K E., (2008). Recyclate fibre- matrix interface analysis for reuse in sheet moulding compounds (SMC). Proceedings of European Conference on Composite Materials (ECCM13). Stockholm, Sweden.

19. Palmer J, Ghita O R, Savage L, and Evans K E., (2009a) "Successful Closed Loop Recycling of Thermoset Composites Part A", Journal of Applied Science and Manufacturing, 40 (4) 490-498

20. Palmer J, Ghita O R, Savage L, Evans E K., (2009b). New automotive composites based on glass and carbon fibre recyclate. Proceeding of International Conference for Composite Materials (ICCM 17). Edinburgh, UK.

21. Pickering S J., (2006) Recycling technologies for thermoset composite materials- current status. Comp A: Appl Sci Manuf ;37 (8):1206-15.

22. PIM project TP-K1042A funded by TSB, (2006-2009)

23. Recycling and Recovery of Plastics, Editor Brandrup J., Hanser Publishers 1995 (ISBN 344618258 6)

24. Recycling Handbook. Editor John T Aquino, Lewis Publications 1995 (ISBN: 156670 $068 \mathrm{X}$ )

25. Recycling and Recovery from Composite Materials 1995 - 1997, DTI LINK Structural Composite Programme

Brunel University, Wolfson Centre for Materials Processing and University of Nottingham, Department of Engineering.

26. Recycling of PVC and Mixed Plastic Waste, Editor La Mantia F P., Chem. Rec. Publishing 1996 (ISBN 1895198 119)

27. RECCOMP project TP2-10083 funded by TSB, (2005-2008) 
28. Tarverdi K., (2006) Annual Technical Conference, ANTEC Charlotte May 7-11 ISBN: 0-9753707-3-1 Recycling and Reuse of Vinyl Wallpaper,

29. The End of Life Vehicles Regulations 2003, Statutory Instrument 2003 No.2635 ISBN 01 1047841X

30. WRAP, Local Authorities Plastics Collection Survey 2008, ISBN: 1844053873

31. Xia W, Kang Y G, Song J H and Tarverdi K., (2007), Biopolymer composites reinforced with fractioned wheat straw Advances in Eco-materials, Proceedings of the Eight International Conference on Ecomaterials (ICEM8 2007) Vol.1 Brunel Univ. Press

32. Yip H L H, Pickering S J, Rudd C D., (2002) "Characterisation of carbon fibres recycled from scrap composites using fluidised bed process." Plastic Rubber Compos Process Appl. 31(6):278-82.

\subsection{Additional Sources of Information including website references}

Accessed April 2009

http://www.alenia-aeronautica.It

http://www.axionrecycling.com

http://www.bpf.co.uk

http://www.breeam.org

http//www.brunel.ac.uk/research/centres

http://www.bsi-global.com

http://www.centriforce.com

http//www.closedlooprecycling.com

http://www.defra.gov.uk/environment/waste/europe/index.htm

http://www.ec.europa.eu/environment/waste/legislation/a.htm

http://www.environment-agency.gov.uk/business/topics/waste 
http://www.epwin.co.uk

http://www.eu.simsrs.com

http://www.hallmarkpanels.co.uk

$\underline{\mathrm{http} / / \mathrm{www} \text {.iso.org }}$

http://www.letsrecycle.com/prices/plasticsarchive2007.jsp

http://www.mkelectric.co.uk

http://www.pvc group.co.uk

$\underline{\text { http//www.recoup.org }}$

http://www.recovinyl.com

http://www.recovinyl-wrap flyer 2008

http://www.remarkable.co.uk

http://www.theconstructioncentre.co.uk

http://www.therenewableenergycentre.co.uk

http://www.vannplastic.co.uk

http://www.vekauk.com

http://www.wasteonline.org.uk/resources/informationSheet/plastics.html

http://www.wastewatch.org.uk

http://www.wrap.org.uk

http://www.wrap.org.uk/plastics/construction 


\section{Figure 1}

\section{WTOP $\begin{aligned} & \text { Material change for } \\ & \text { a better environment }\end{aligned}$}

\section{Plastics in household waste}

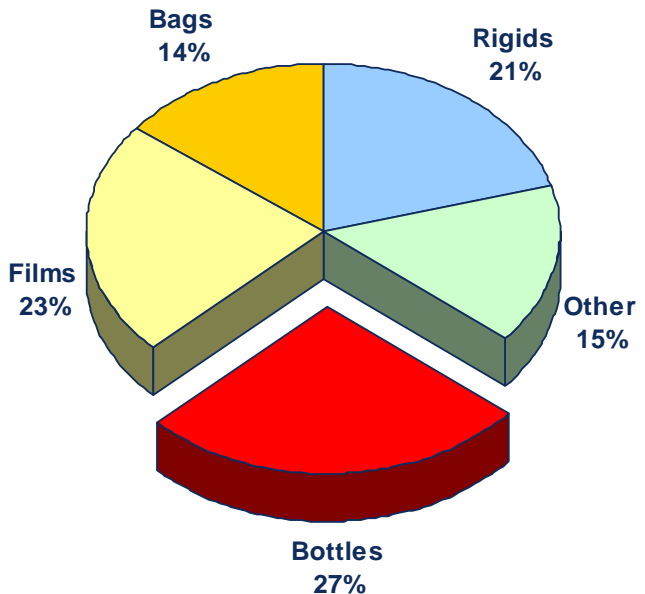

$\sim 1.9 \mathrm{~m}$ tonnes

Figure 2 Recyclates of composites and mixed, contaminated or domestic polymer waste is uneconomical and unattractive to recyclers

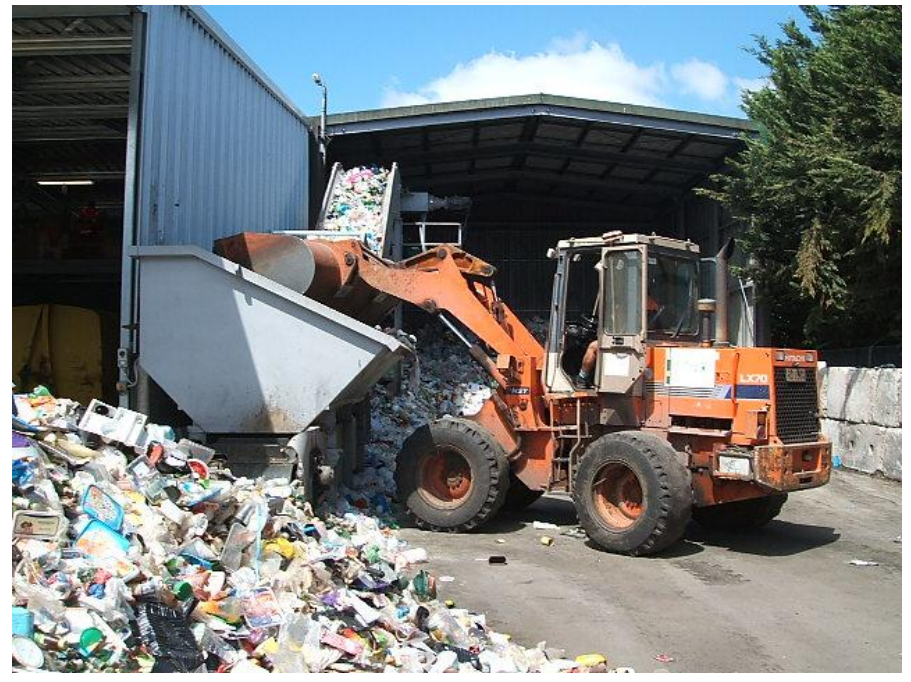

(Curtesy of Paul Gallen of APM Ltd.) 


\section{Figure 3}

Concept of the PIM process that uses micronized mixed plastic waste involves applying a film of virgin polymer to the interior of a hot lower mould tool, which begins to cool the core material comprising of powdered mixed recyclate and blowing agent is then sprayed into the lower mould tool using a spray process. A lid mould also coated with partially cooled film of polymer is then lowered onto the lower mould half and the mould is clamped. The mould is then placed into a core curing oven where the core material fuses together.The mould is then cooled and the product removed

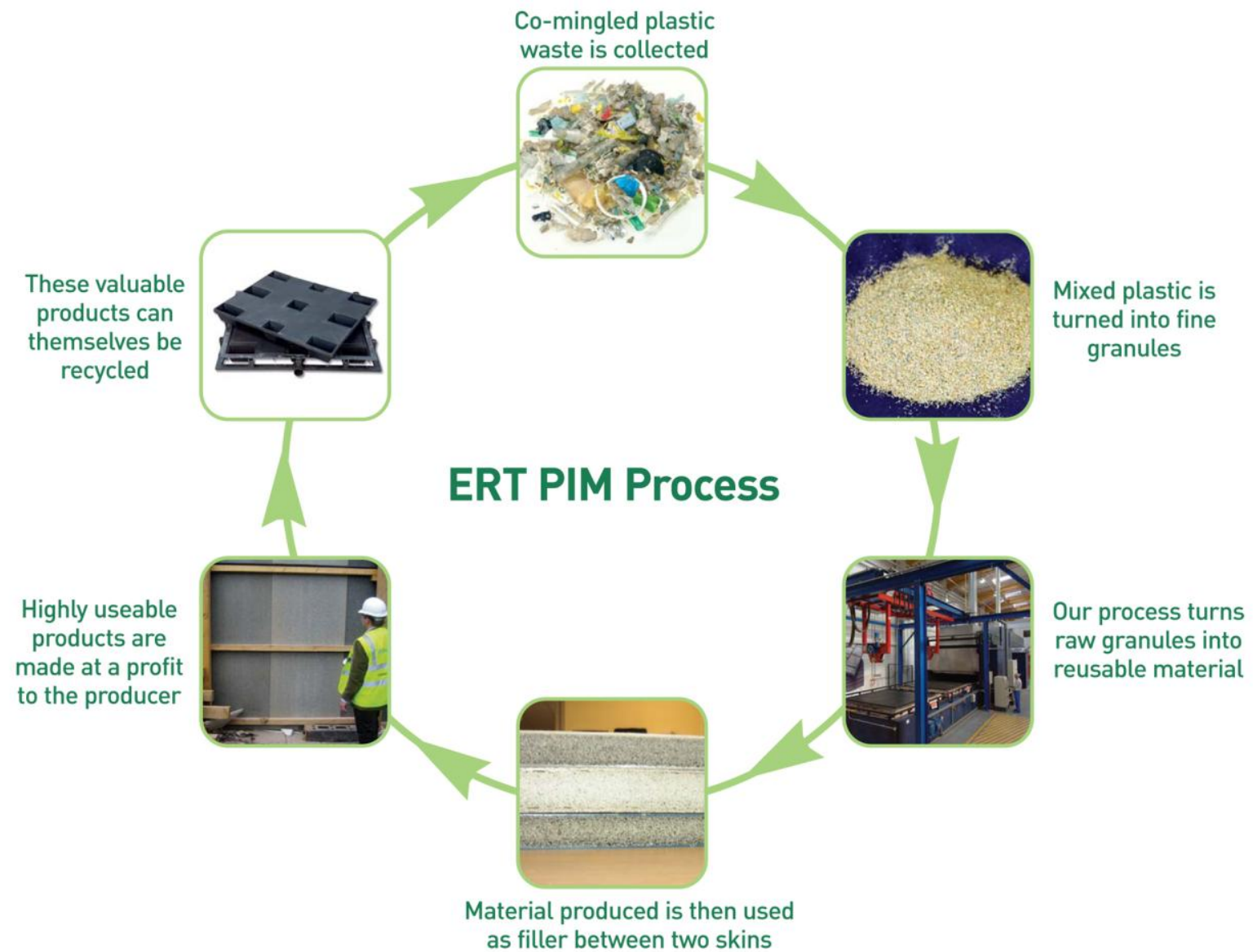




\section{Figure 4a \& 4b}

Trial site by Bovis Lend Lease

Award winning replacement for external plywood sheet, with mixed waste polymer Powder Impression Mouldings

\section{Figure 4a}

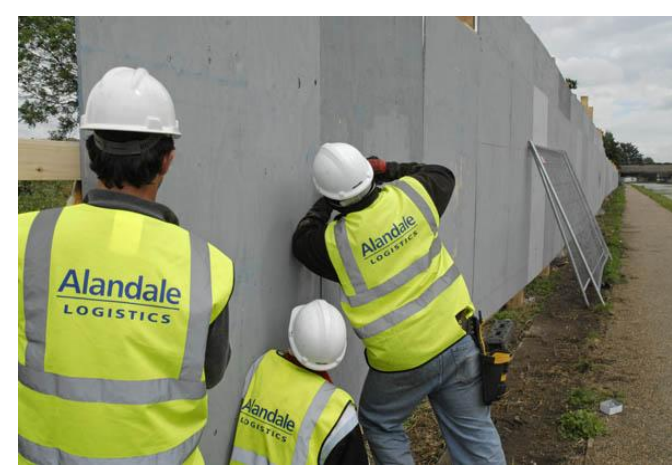

\section{Figure 4b}

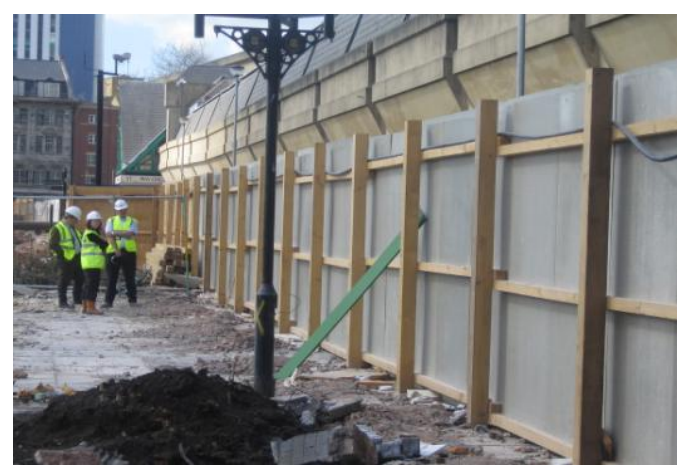

(Trial site by Bovis Lend Lease) 